\title{
An analysis of second time around bankruptcies using a split-population duration model
}

\author{
Arindam Bandopadhyaya , Sanjiv Jaggia
}

\begin{abstract}
A significant proportion of firms that reorganize under Chapter 11 file for a second Chapter 11 protection or liquidate. We use a "split-population" duration model that provides useful information regarding factors that could lead to a second bankruptcy. We find that the probability (hazard) of a firm re-entering bankruptcy is lower for firms that take a long time to reorganize, reduce their debt-to-assets ratio, do not divest, belong to an industry that has low capacity utilization and low demand growth. We also find that the probability of an average firm re-entering bankruptcy increases for about 4 years before declining.
\end{abstract}

JEL classification: C41; G33

Keywords: Bankruptcy; Split-population duration model; Chapter 11

\section{Introduction}

Since the modification of the bankruptcy laws in 1978 the provision under Chapter 11, where financially distressed firms can seek the protection of the court from its creditors, has been under close scrutiny. Some observers argue that reorganization of a firm under Chapter 11 may not have been successful if it subsequently files for another bankruptcy. Hotchkiss (1995) reports that almost $40 \%$ of the firms in her sample continue to experience operating losses in the 2 
years following emergence from Chapter 11 protection and 15\% of the firms re-enter Chapter 11 a second time. LoPucki and Whitford (1993) and Gilson (1996) also find a large incidence of firms filing for bankruptcy or restructuring their debt a second time.

However, in the presence of liquidation costs (Shleifer and Vishny, 1992) and agency costs (Mooradian, 1994), a reorganization under Chapter 11 can be successful even if the firm files for a second Chapter 11 protection, as long as the cash flows to the firm's claimants exceed what they would have been in liquidation. Despite the argument that a second bankruptcy is not necessarily a failure, whether a firm re-enters bankruptcy remains an important issue to policy makers who monitor the bankruptcy process and also to the creditors and the stockholders of reorganized firms.

In this paper, we address the following issues: How long does it take before a firm that has been reorganized under Chapter 11 files for a second Chapter 11 protection or liquidate (henceforth referred to as "the firm re-entering bankruptcy")? What is the probability that an average firm will never file for another bankruptcy? Is the relative vulnerability to another bankruptcy influenced by firm-specific differences or by changes in industry and economy-wide conditions? In order to address these issues, we observe firms that file for Chapter 11 and subsequently emerge as reorganized firms between 1979 and 1990. We track these firms until 1993 to determine if they re-enter bankruptcy. The variable of interest is the time to the second bankruptcy filing, which enables us to analyze the vulnerability of a firm over time. We examine how the characteristics of the firm and the general business environment in which the firm operates affect this variable. Some firms in the sample have not re-entered bankruptcy by the end of 1993. These firms might re-enter bankruptcy after 1993 (giving rise to censored observations) or might continue to operate without ever re-entering bankruptcy. A split-population duration model (see Schmidt and Witte, 1989) is used in the estimation. The duration model incorporates censoring to estimate the instantaneous probability (hazard) of a reorganized firm re-entering bankruptcy. The "split" parameter is included to control for the fact that some firms may never go bankrupt once they have emerged from Chapter 11.

The hazard is specified as a function of firm specific characteristics, industry and economy-wide factors. This hazard is also influenced by the time elapsed after emergence from Chapter 11. A lower hazard at a point in time implies a smaller instantaneous probability of re-entering bankruptcy. We find that firms with a lower hazard: (a) have spent a longer period of time under their first reorganization, (b) have had a larger reduction in their debt-to-assets ratio during reorganization, (c) have experienced a smaller decrease in their lines of businesses during reorganization, (d) are part of an industry that had a lower capacity utilization at the time of emergence, and (e) belong to a low demand growth industry. We also find that the estimated hazard of an average firm goes up for about 4 years before it begins to decline. This result suggests that a firm that emerged, say, 4 years ago 
is more likely to encounter another bankruptcy as compared to a firm that emerged 2 years ago. These results are conditional on the fact that some firms may never eventually re-enter bankruptcy. For an average firm probability of eventually re-entering bankruptcy is approximately $73 \%$.

The rest of the paper is organized as follows. In Section 2, the dependent and the independent variables are described. The methodology used is discussed in Section 3. Results and interpretation appear in Section 4. Section 5 concludes.

\section{Description of the variables}

\subsection{The dependent variable}

A list of firms that filed for protection under Chapter 11 between 1979 and 1990 is obtained from the annual reports of the Securities and Exchange Commission (SEC). This document and the Corporate Changes Reporter (CCR) are used to determine which of these firms are reorganized. The filing and the emergence years are denoted by $t_{\mathrm{f}}$ and $t_{\mathrm{e}}$, respectively. After a firm has emerged from Chapter 11 protection it is tracked until 1993, the year that is chosen for the end of our study. ${ }^{1}$ A record of whether or not during this period the firm either re-enters Chapter 11 protection or files for liquidation under Chapter 7 is made. The exact filing and emergence dates of the first reorganization and the date of re-entry into a second bankruptcy are obtained from the CCR, the Directory of Obsolete Securities (DOS), the Wall Street Journal Index (WSJI) and the Bankruptcy Almanac (BA). If no information on the firm re-entering bankruptcy from $t_{\mathrm{e}}$ until 1993 is obtained in the above publications, it is assumed that the firm continues to operate. To verify that the firm is indeed operating, the Standard and Poor's Register of Corporations, Directors and Executives and the Compustat database are used. This is done to ensure that just because the CCR, DOS, WSJI or the BA does not report a re-entry into bankruptcy, it is not erroneously assumed that the firm continues to operate. ${ }^{2}$

\footnotetext{
${ }^{1}$ Ten firms from our original data set are deleted from the sample because they are merged or acquired as a part of the reorganization plan. This is necessary since it is not possible to track merged or acquired firms to determine if they re-enter bankruptcy. For example, Evans Products (which filed for protection on March 12, 1985 and emerged on July 2, 1986) merged with Grossman's as a part of the reorganization plan. It is not possible to determine if Evans Products re-enters bankruptcy since only Grossman's can be tracked after July 2, 1986. However, there are a few instances when the firm continues to operate as a separate entity even after the merger. For example, HRT Industries. (which filed for protection on November 23, 1982 and emerged on February 10, 1984) merged into a subsidiary of McCrory, effective April 19, 1985. We are able to track HRT Industries since it continued to operate as a separate entity. Few firms merge after a significantly long time after emergence and are treated as censored observations.

${ }^{2}$ For example, Altec (which filed for protection on September 26, 1983 and emerged on May 21, 1987) is dropped from the sample because no additional information regarding this firm is available after 1988 from any of the above-mentioned publications and the Compustat database. We drop 23 firms for this reason.
} 


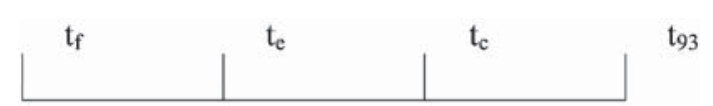

Fig. 1. The sequence of events after the firm's first Chapter 11 filing. $t_{\mathrm{f}}$ is the date the firm files for Chapter 11 protection; $t_{\mathrm{e}}$ is the date the firm emerges from Chapter 11 protection; All emerged firms (107) are tracked until the end of 1993. Forty-two firms re-enter bankruptcy and 65 continue to operate; The dependent variable is $\left(t_{\mathrm{c}}-t_{\mathrm{e}}\right)$ for firms that re-enter bankruptcy (completed observation) and $\left(t_{93}-t_{\mathrm{e}}\right)$ for firms that continue to operate until 1993 (censored observation); $\left(t_{\mathrm{e}}-t_{\mathrm{f}}\right)$ is the time taken to reorganize the first time and is used as an independent variable.

The dependent variable is the time (duration) between the firm's emergence from Chapter 11 and the firm's re-entry into bankruptcy. This variable enables us to analyze the vulnerability of firms over time. The sequence of events after a firm files for its first Chapter 11 protection is described in Fig. 1 where the dependent variable is $\left(t_{\mathrm{c}}-t_{\mathrm{e}}\right)$ for completed observations and $\left(t_{93}-t_{\mathrm{e}}\right)$ for censored observations. Data are available for 107 firms, of which 42 firms re-enter bankruptcy. ${ }^{3}$ Note that the recidivism in our sample is larger than in a related study by Hotchkiss (1995). She tracks reorganized firms for 3 years and firms that have not re-entered bankruptcy by that time are implicitly treated as ones that will never do so. We find that $57 \%$ of the firms in our sample that re-enter bankruptcy do so after 3 years.

A firm that does not re-enter bankruptcy results in a censored observation since we do not when, and indeed if, such a firm will file for bankruptcy. Thus, the sample consists of completed and censored durations. The frequency distribution of firms re-entering bankruptcy is presented in Fig. 2. These firms are associated with completed observations since the exact duration of time to bankruptcy on only these firms is known. For the firms that re-file for bankruptcy, it takes an average time of 3.6 years. A large proportion of firms re-entering bankruptcy do so within 6 years of their re- organization, with only four firms taking more than 6 years.

\subsection{The independent variables}

The following independent variables represent the postulated firm specific, industry and economy-wide factors that contribute to the future success of a reorganized firm.

\footnotetext{
${ }^{3}$ Seventeen firms are dropped from the sample because firm specific variables are not available from: (a) Compustat, (b) Disclosure (c) Moody's Manuals (d) the firm's annual 10K filings with the SEC.
} 


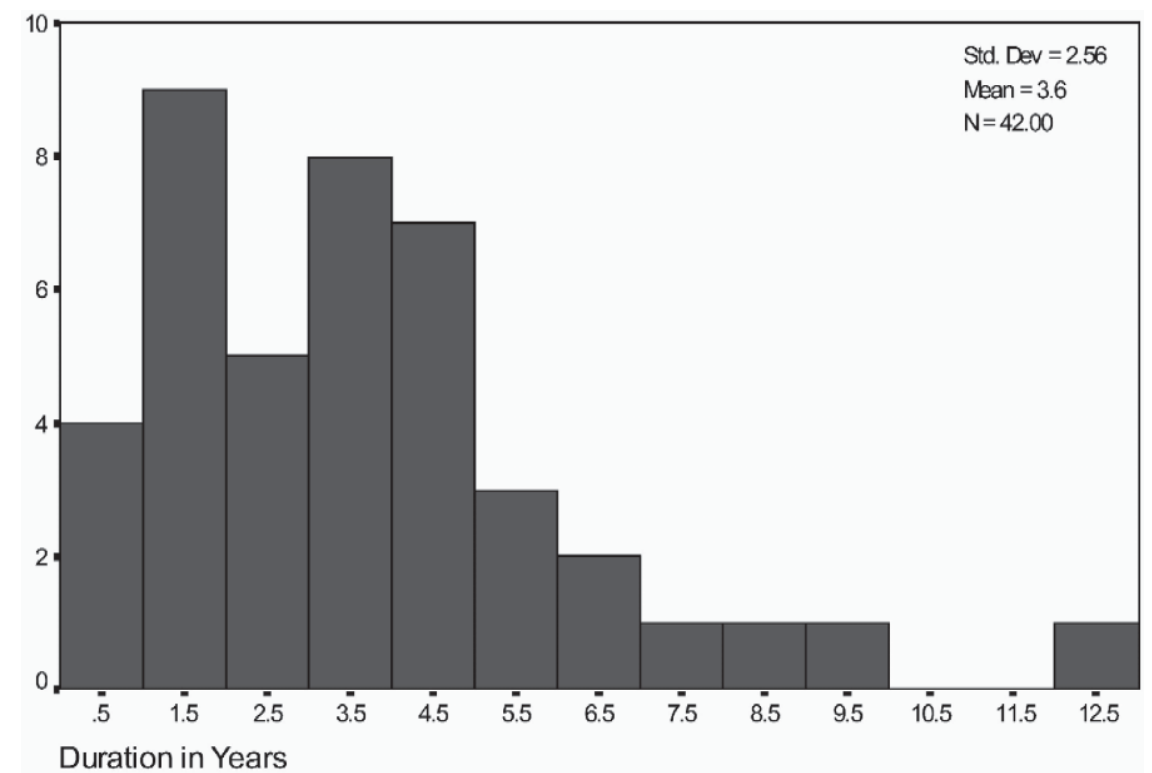

Fig. 2. Frequency distribution of firms that re-enter bankruptcy.

\subsubsection{The time the firm spends under Chapter 11 (Duration 1)}

This is defined as the period between $t_{\mathrm{f}}$ and $t_{\mathrm{e}}$, the time the firm spends under Chapter 11 protection while it reorganizes. There are several reasons for the inclusion of Duration 1 as a control variable. Many authors (see, e.g., Jensen, 1989; Gilson et al., 1990) point out that the primary disadvantage of reorganization under Chapter 11 is its relative cost. Both direct costs (fees to accountants and lawyers) and indirect costs (lost sales or profits due to the constraints imposed by the trustee) of Chapter 11 filing depend on the length of a firm's stay under Chapter 11 protection. A higher cost of reorganization could enhance the possibility of future financial difficulties. On the contrary, a longer time in Chapter 11 may provide the firm with sufficient protection needed to reorganize successfully (see Maksimovic and Phillips, 1998). For these reasons the effect of Duration 1 on the failure probability is ambiguous, a priori.

2.2.2. Assets of the firm when it emerges from its first Chapter 11 protection (Log Assets)

This variable, measured by the natural log of total assets at the time the firm emerges from Chapter 11, is included to control for firm size. In general, large firms have greater ability to raise additional funds in the capital market (White, 1984; Casey et al., 1986). It is expected that the larger the firm the lower is the probability of the firm re-entering bankruptcy. 
2.2.3. The change in the leverage of the firm during reorganization (Change in Debt / Assets)

This variable, measured by the difference between the debt-to-assets ratio of the firm at the time it emerges from the time it files for Chapter 11, is included to capture the ability of the firm to lower its indebtedness. A firm in financial distress is likely to have a high debt-to-assets ratio. Opler and Titman (1994) show that high debt adversely affects operating performance since in an industry downturn, high debt firms lose more sales than firms with low debt. It is important to note that high debt ratios may actually be the optimal capital structure for a reorganized firm. For instance, Harris and Raviv (1990) and Hart and Moore (1995) show that high levels of debt curbs the managers' ability to make unprofitable but empirebuilding investments, and to trigger liquidation if the firms' assets become more valuable elsewhere. However, it is postulated that a higher debt-to-assets ratio, irrespective of its optimality, contributes to a greater risk of the firm encountering another bankruptcy. ${ }^{4}$

\subsubsection{The change in the CEO while the firm undergoes reorganization (Change in} CEO)

Some observers contend that the Chapter 11 process is inefficient, in part, because of the provision of the bankruptcy code that allows incumbent management to retain control of the firm in bankruptcy and propose a reorganization plan. It is alleged that managers acting on the behalf of the shareholders (Bebchuk and Chang, 1992) and in their own self-interest (Boot, 1992) are biased towards the continuation of an insolvent firm. Jensen (1993) adds that when managers shut plants or liquidate firms, this process “ ... causes personal pain, creates uncertainty and interrupts or sidetracks careers. Rather than confronting this pain, managers generally resist such action as long as they have cash flow to subsidize the losing operations." The CEO change variable is included to examine if a change in management (or lack thereof) has an impact on the future success of the firm. If the incumbent management does indeed bias the Chapter 11 process towards the continuation of inefficient firms, then firms that appoint a new CEO during reorganization should have a lower probability of re-entering bankruptcy.

\subsubsection{The change in the number of lines of businesses during reorganization} (Change in \#SIC)

It is argued that firms that are more diversified at the time of the Chapter 11 filing are more successful after emergence, since they have the capability to operate after divesting unsuccessful lines of businesses. The immediate benefit of

\footnotetext{
${ }^{4}$ In fact, our raw data suggest that of the 20 firms with the highest value of Change in Debt/Assets, 11 re-entered bankruptcy by 1993. By comparison, only six firms out of the 20 with the lowest value re-enter bankruptcy.
} 
divesting is an increase in liquidity and a return to core lines of businesses. However, since the market for assets of a bankrupt firm is generally thin, it is easier for firms to sell only those assets that are in relatively high demand. Maksimovic and Phillips (1998) find that bankrupt firms that sell and close plants over time are associated with a decrease in overall firm performance. The Change in \#SIC variable, measured by the change in the number of 4-digit Standard Industrial Classification (SIC) codes listed for the firm during reorganization, is included to control for these factors. The impact of this variable on the likelihood of future success of the firm is ambiguous.

\subsubsection{Industry capacity utilization when the firm emerges from Chapter 11 (Capacity Utilization)}

Often, firm performance is dictated by industry-wide conditions. Lang and Stulz (1992) find that the performance of a firm is affected by Chapter 11 filings by other firms in the industry. Shleifer and Vishny (1992) argue that the market for a firm's assets will be illiquid when other firms in the same industry are also distressed. John et al. (1992) find that distressed firms often cite exogenous, industry shocks as causes for their decline. The Capacity Utilization variable is included to control for these factors. However, a comparison of good vs. bad industry conditions cannot be made accurately based solely on the capacity utilization rate since capacity utilization generally differs across industries at all times. Therefore, we define a variable that represents the capacity utilization of the industry in the year the firm emerges from Chapter 11, deflated by the industry peak capacity utilization in the previous business cycle. ${ }^{5}$ The operating performance of the firm's industry relative to peak performance has two counteracting forces on the hazard of a firm re-entering bankruptcy. A healthy industry implies that a firm in that industry has a better chance of survival as compared to a similar firm in a poorly performing industry. However, a high capacity utilization might be the reason that the bankrupt firm was able to emerge from Chapter 11 protection, although inherently the firm was not financially viable. Thus, this variable has an ambiguous impact on the firm's probability of another bankruptcy.

\subsubsection{Industry growth over a 10-year period (Demand Growth)}

This is another variable that controls for industry-specific differences. It measures the long-term growth prospects of an industry. ${ }^{6}$ Unlike, the capacity utilization variable that is computed at the emergence year, the demand growth variable is computed for a fixed period between 1982 and 1992. This allows demand growth to be more industry specific as compared to the capacity utilization variable that may also be influenced by idiosyncratic economy-wide condi-

\footnotetext{
${ }^{5}$ For our sample period, the monthly highs for the previous business cycle occurred in 1988-1989.

${ }^{6}$ Maksimovic and Phillips (1998) point out that this variable also captures cost shifts from increased foreign imports or shocks to production costs, as well as demand changes in the industry.
} 
tions in the year the firm emerges from Chapter 11. Maksimovic and Phillips (1998) show that the average productivity of firms that become bankrupt, plant closures and asset sales during bankruptcy, and the optimal resolution of bankruptcy depend on the level of industry demand. A higher proportion of firms that file for bankruptcy are from low demand growth industries. However, while bankrupt firms in low demand growth industries do not have significantly lower productivity than their industry counterparts, those in high demand growth industries are under-performers. Given these findings it is postulated that the higher the industry demand growth the greater is the probability of re-entering bankruptcy.

2.2.8. The rate of growth of the Gross Domestic Product (GDP) during the time the firm emerges from Chapter 11 (GDP Growth)

This variable, measured by the 3-year average GDP growth after the firm emerges from Chapter 11, is included to control for economy-wide factors that affect the general environment in which the firm is operating. A priori, the effect of the GDP Growth variable on the hazard is similar to the impact of the Capacity Utilization variable. A relatively healthy economy at the time of the emergence of the firm from Chapter 11 may result in a better chance of survival as compared to a similar firm that emerges from protection at a time when the economy is performing relatively poorly. However, a high GDP growth might have assisted the firm to emerge from Chapter 11 protection, although the firm was not sufficiently healthy. Thus, this variable also has an ambiguous impact on the firm's probability of another bankruptcy.

The actual filing and emergence dates used to compute Duration 1 are obtained from CCR, DOS, WSJI and BA. The total assets of the firm at $t_{\mathrm{e}}$ are used to compute Log Assets. The long-term debt/total assets ratio of the firm is obtained for $t_{\mathrm{e}}$ and $t_{\mathrm{f}}$ and the difference is used to calculate Change in Debt/Assets. Data on Log Assets and Change in Debt/Assets are obtained from Compustat, Disclosure, Moody's Manuals and 10K filings of the firm with the SEC.

The Standard and Poor's Register of Corporations, Directors and Executives is used to collect data on the Change in CEO and the Change in \#SIC variables. For each firm the names of the CEO as well as the number of 4-digit SIC categories listed are obtained for $t_{\mathrm{f}}$ and $t_{\mathrm{e}}$. By comparing the names, the Change in CEO variable is constructed. If over time this position is created or dropped then it is recorded as a change. The Change in \#SIC is constructed by taking the difference between the number of SIC listings at $t_{\mathrm{e}}$ and $t_{\mathrm{f}}$. To obtain the Capacity Utilization variable, we first classify firms according to their SIC code at the time of emergence. The capacity utilization corresponding to the firm's industry for the year it emerged from protection, and the peak industry capacity utilization for the previous business cycle are obtained from the Federal Reserve Bulletin. The demand growth variable is also constructed on the basis of SIC codes. For each firm, its industry growth rate between 1982 and 1992 of the value of product shipments is computed. The value of product shipments is available for the 
Table 1

Descriptive statistics of explanatory variables

\begin{tabular}{lcclr}
\hline Variables & Mean & Median & $\begin{array}{l}\text { Standard } \\
\text { deviation }\end{array}$ & $\begin{array}{c}\text { Difference } \\
\text { in means }\end{array}$ \\
\hline Duration 1 & 1.973 & 1.728 & 1.257 & $0.597^{\text {a }}$ \\
Log Assets & 3.748 & 3.719 & 2.289 & $-0.867^{\mathrm{a}}$ \\
Change in Debt/Assets & 0.079 & 0.012 & 0.337 & $0.113^{\mathrm{a}}$ \\
Change in CEO & 0.505 & 1.000 & 0.502 & -0.086 \\
Change in \#SIC & -0.551 & 0.000 & 3.286 & 0.163 \\
Capacity Utilization & 94.25 & 95.16 & 4.793 & -0.432 \\
Demand Growth & 0.707 & 0.676 & 0.845 & 0.170 \\
GDP Growth & 2.455 & 2.642 & 1.205 & 0.125 \\
\hline
\end{tabular}

- Duration 1: the number of years that the firm spends under Chapter 11.

- Log Assets: natural log of assets, in millions of US\$, of the firm at emergence.

- Change in Debt/Assets: the change in the debt-to-assets ratio during reorganization.

- Change in CEO: 1 if CEO changes during reorganization; 0 otherwise.

- Change in \#SIC: the change in the number of 4-digit SIC listings during reorganization.

- Capacity Utilization: the capacity utilization of the industry of the firm at emergence.

- Demand Growth: the industry growth rate of the firm between 1982 and 1992.

- GDP Growth: the average GDP growth rate of 3 years after the emergence.

${ }^{\mathrm{a}}$ Denote significance at $5 \%$.

* Represents the difference in means between the firms that re-enter bankruptcy and the ones that continue to operate at the end of 1993.

manufacturing industries. For other industries, similar measures are used to calculate demand growth. For example, the value of construction work is used to compute the demand growth for the construction industries. The data are obtained from various publications of the Census Bureau. The GDP is obtained from the International Financial Statistics database. Three-year moving averages for GDP growth are created using the series.

Descriptive statistics on the independent variables appear in Table 1. The mean, the median and the standard deviation are reported in the first three columns using all the firms in the sample. The last column reports the difference in means of the variables between the firms that re-enter bankruptcy and the ones that continue to operate at the end of 1993 . We find that the means are significantly different at $5 \%$ for the Duration 1, the Log Assets, and the Change in Debt/Assets variables. The averages of all the firms in the sample indicate that the average firm:

(a) spends almost 2 years in its first reorganization,

(b) at the time of emergence has total assets of US\$509 million with a high standard deviation of US\$2,660 million. The median assets are US\$41 million. ${ }^{7}$

\footnotetext{
${ }^{7}$ The natural log of total assets is used as an independent variable to control for a high variability and skewness of total assets. Results do not change qualitatively when total assets is used instead.
} 
(c) emerges as a firm with a slightly higher debt-to-assets ratio,

(d) has a $50.5 \%$ chance of a change in CEO while it reorganizes,

(e) undergoes a reduction in the number of lines of businesses it owns while it reorganizes,

(f) is part of an industry that has a capacity utilization relative to peak capacity of $94.25 \%$ in the firm's emergence year,

(g) is part of an industry that has a 10-year demand growth of $70.7 \%$,

(h) operates in an environment where the average GDP growth 3 years after emergence from reorganization is $2.45 \%$.

The 107 firms are distributed across 83 different 4-digit SIC categories. The largest concentration is in the "eating places" and "variety stores" industries with six and four firms, respectively. Overall, there are 15 industries that have two or more firms.

\section{The methodology}

Since the dependent variable is a duration, the appropriate estimation methodology is duration (alternatively known as hazard rate) models. As is customary in applications of duration models, it is the hazard rate that is analyzed. The hazard rate is the instantaneous probability of an agent making a transition from one state to another, given that the transition has not already occurred. In the context of this paper, the hazard is the instantaneous probability that a firm that has emerged from Chapter 11 protection moves from a solvent to a bankrupt state.

An implicit assumption made in most survival time models is that of certain exit, which in this context implies that all reorganized firms will eventually go bankrupt. We use a split-population duration model (see Schmidt and Witte, 1989) that takes into account the possibility that the transition from one state to another may never occur. This adjustment is appropriate since the firm that has emerged from Chapter 11 once may never re-enter bankruptcy. Thus, the probability that a firm will eventually fail is postulated to be less than one. The model estimates the instantaneous probability of failure (hazard) at a point in time along with the probability of eventual failure.

Duration models are represented in terms of the density, survivor, and hazard functions, denoted by $f(t ; X), S(t ; X)$, and $h(t ; X)$, respectively. The duration variable is $T$ which denotes the length of time that a reorganized firm takes to re-enter bankruptcy. These functions are conditional on the independent variables, $X .^{8}$ The likelihood function consists of $f(t ; X)$ for completed durations and

\footnotetext{
${ }^{8}$ See Kiefer (1988), Jaggia and Thosar (1995) and Baek and Bandopadhyaya (1996) for a description and applications of standard duration model and Gucht and Moore (1998) for a split-population model.
} 
$S(t ; X)$ for censored observations. The survivor function captures the fact that the duration of the observation is at least as long as implied by the censoring point. Let $C$ be an indicator variable that equals 1 if the duration is complete and 0 if it is censored. The duration is complete for firms that re-enter bankruptcy, and censored for those firms that do not, during the observation period. The standard duration model assumes that censored firms will eventually re-enter bankruptcy.

The split-population duration model allows the possibility that some censored firms may never re-enter bankruptcy. Let $U$ be an unobservable variable that equals 1 if the firm eventually fails and 0 otherwise. Then,

$$
P(U=1)=\delta, \quad P(U=0)=1-\delta .
$$

Here, $\delta$ is the "split-population parameter" that denotes the probability of eventual failure. If $\delta<1$, then a proportion of the censored firms will never re-enter bankruptcy. For a firm that has re-entered bankruptcy, we have $T=t$ and $C=1$. The appropriate density for such a firm is therefore,

$$
P(U=1) f(t ; X, U=1)=\delta f(t ; X, U=1) .
$$

For a censored observation $(C=0)$, all we know is that the firm has not re-entered bankruptcy during the observation period. We entertain two possibilities, (a) that the firm would have re-entered if it were followed longer and (b) that this firm would never re-enter bankruptcy. Specifically,

$$
\begin{aligned}
P(C=0) & =P(U=0)+P(U=1) P(T>t ; X, U=1) \\
& =1-\delta+\delta S(t ; X, U=1) .
\end{aligned}
$$

The likelihood function consists of expressions (2) and (3) above for completed and censored durations, respectively. This likelihood function can be constructed once the hazard function is parameterized. In this paper, we use a log-logistic hazard function that has a property that it declines for sufficiently large $T$. This function is appropriate since, for a reorganized firm that has operated successfully for a reasonably long period of time, the probability of re-entering bankruptcy is expected to decline. The log-logistic hazard function is given by:

$$
h(t ; X, U=1)=\exp (X \beta) \alpha t^{\alpha-1}\left(1+\exp (X \beta) t^{\alpha}\right)^{-1} .
$$

$X \beta=\beta_{0}+\beta_{1} X_{1}+\beta_{2} X_{2}+\ldots+\beta_{k} X_{k}$ and the $X_{j}$ 's are the firm-specific, industry and economy-wide variables and $\alpha$ is the shape parameter of the hazard. It is useful to note that if a variable has a positive impact on the hazard, then it has a negative impact on the duration to second bankruptcy. The log-likelihood function for a split-population model that uses (4) to compute (2) and (3) above is:

$$
\begin{aligned}
\ln L= & \sum_{i=1}^{N} C[\ln \delta+\ln \alpha+w-2 \ln (1+\exp (w))] \\
& +(1-C)\left[\ln \left(1-\delta+\delta(1+\exp (w))^{-1}\right)\right]
\end{aligned}
$$


where $w=X \beta+\alpha \ln t$ and the $X$ 's are all the independent variables discussed in Section 2.2. The split parameter $\delta$ allows the probability of eventual failure to be different from one and if the estimated $\delta$ is not significantly different from 1 , the split model is converges to a standard hazard model. ${ }^{9}$ The parameter estimates are obtained by maximizing the above log-likelihood function. ${ }^{10}$

\section{Results and interpretation}

In our model we estimate the probability of a second bankruptcy given the firm specific and other factors at the time the firm emerges from its first bankruptcy, and the time path of this probability. Parameter estimates from the split log-logistic model appear in Table 2. We also include in this table the estimates from the standard log-logistic model for comparison. Although the results of the two models are similar in terms of the sign and significance of the variables, the split parameter model is more appropriate. We find that the estimate of the split parameter is 0.727 and is significantly different from one at any level of significance. The estimate implies that an average reorganized firm faces only a $73 \%$ probability of another bankruptcy. For an individual firm, cross-sectional differences are captured by the hazard function. At any given point after reorganization, the hazard will differ between firms. Further, the hazard varies over time.

We begin with a discussion of the impact of the characteristics of the firm and the general business environment in which the firm operates on the instantaneous probability of the firm re-entering bankruptcy. ${ }^{11}$ The time the firm spends under Chapter 11 the first time (Duration 1) has a significant, negative influence on the hazard. This implies that the longer a firm spends under its first reorganization, the lower is the hazard of a subsequent bankruptcy. A longer reorganization process is often perceived as inefficient, because it imposes higher bankruptcy costs. However, as documented by Maksimovic and Phillips (1998), a relatively longer protection period enables many firms in bankruptcy to enhance their level of productivity, which makes the costs related to bankruptcy worthwhile to incur.

\footnotetext{
${ }^{9}$ It should be mentioned that $\delta$ can also be a function of the $X$ variables that are used in the hazard. However, as pointed out by a referee, since economic theory provides no direction, it is difficult to identify the influence of the same variable on both the hazard and the probability of eventual failure.

${ }^{10}$ Maximum likelihood estimates are obtained using the MAXLIK module of the GAUSS programming language. Consistent estimate of the variance-covariance matrix of the parameters is derived as $H^{-1}\left(G^{\mathrm{T}} G\right) H^{-1}$ where $H$ and $G$ denote the Hessian and the gradient evaluated at the maximum likelihood estimates of the parameters.

${ }^{11}$ Although we discuss the sign and significance of the hazard parameters $(\beta)$, it should be pointed out that the magnitude of the influence of the factors also depends on the estimated value of $\delta$. Therefore, the marginal contribution of a factor on the probability of a second bankruptcy depends on the estimated eventual failure probability of 0.727 .
} 
Table 2

Estimates of log-logistic and split-population log-logistic models

\begin{tabular}{lll}
\hline Variables & Log-logistic model & $\begin{array}{l}\text { Split-population } \\
\text { log-logistic model }\end{array}$ \\
\hline Constant $\left(\beta_{0}\right)$ & $-11.11^{\mathrm{b}}(-1.597)$ & $-18.10^{\mathrm{a}}(-2.196)$ \\
Duration $1\left(\beta_{1}\right)$ & $-0.482^{\mathrm{a}}(-3.118)$ & $-0.657^{\mathrm{a}}(-3.487)$ \\
Log Assets $\left(\beta_{2}\right)$ & $-0.158^{\mathrm{b}}(-1.302)$ & $-0.175(-1.206)$ \\
Change in Debt $/$ Assets $\left(\beta_{3}\right)$ & $1.671^{\mathrm{a}}(3.002)$ & $1.542^{\mathrm{a}}(2.709)$ \\
Change in CEO $\left(\beta_{4}\right)$ & $0.154(0.326)$ & $0.372^{(0.549)}$ \\
Change in \#SIC $\left(\beta_{5}\right)$ & $-0.073(-1.091)$ & $-0.541^{\mathrm{a}}(-3.463)$ \\
Capacity Utilization $\left(\beta_{6}\right)$ & $0.087(1.204)$ & $0.162^{\mathrm{a}}(1.894)$ \\
Demand Growth $\left(\beta_{7}\right)$ & $0.275^{\mathrm{b}}(1.374)$ & $0.398^{\mathrm{b}}(1.391)$ \\
GDP Growth $\left(\beta_{8}\right)$ & $0.218(0.843)$ & $0.160(0.451)$ \\
$\alpha$ & $1.734^{\mathrm{a}, *}(3.656)$ & $2.210^{\mathrm{a}, *}(4.227)$ \\
$\delta$ & & $0.727^{\mathrm{a}, *}(2.638)$ \\
\hline
\end{tabular}

The $t$-statistics are presented in the parentheses.

- The coefficients $\beta$ 's capture the influence of the regressors on the hazard.

- The shape parameter $\alpha$ determines the point after which the hazard declines.

- The split parameter $\delta$ represents the probability of eventual failure.

${ }^{a}$ Denote significance at $5 \%$.

${ }^{\mathrm{b}}$ Denote significance at $10 \%$.

* For $\alpha$ and $\delta$, the $t$-statistic is evaluated at 1 .

The change in the debt-to-assets ratio variable is significant with a positive coefficient. The higher the debt-to-assets ratio at the time of emergence relative to the ratio at the time of filing the greater is the hazard. This result is of significant importance since we find that the average firm in our sample emerges with a higher debt-to-assets ratio as compared to when it files for protection. Gilson (1996) also reports an increase in leverage during reorganization and reports a higher incidence of recurring bankruptcy for firms that remain more leveraged after restructuring their debt. Our result is consistent with the argument that firms that emerge from bankruptcy with relatively high debt ratios are adversely affected by the leverage (Opler and Titman, 1994) and are ones that have poor growth opportunities (Alderson and Betker, 1995). As argued before, a relatively high debt/asset ratio may be optimal for the firm, an argument that is not contradictory to our finding. Firms that emerge with high debt ratios that are optimal are ones whose monitors have determined that the high leverage is necessary to impose discipline on the managers and use it as a means to trigger liquidation if necessary. Perhaps, high leverage can be interpreted as a signal that the firm is more likely to encounter another bankruptcy because its growth opportunities are likely to be limited and/or the stakeholders have perceived that liquidation is a possibility.

The change during reorganization of the number of SIC codes listed for the firm has a negative impact on the hazard. The more the number of lines of businesses that the firm has, at the time it emerges relative to when it filed for protection, the lower is the hazard. The average firm in our sample emerges with a 
smaller number of lines of businesses. This is consistent with the finding in John et al. (1992) that, in response to decline in earnings, diversified firms retrench quickly and increase their focus on core operations. Our result indicates that, on balance, for the future viability of the firm excessive divesting may not be prudent. This could be because bankrupt firms seeking liquidity often have to sell their more profitable lines of businesses leaving the firm with plants that are less productive (Maksimovic and Phillips, 1998), which contributes to a higher probability of repeated bankruptcy in the future.

The capacity utilization variable is significant with a positive sign. This indicates that the higher the capacity utilization of the firm's industry relative to peak performance at the time of emergence, the greater is the probability of the firm re-entering bankruptcy. Bandopadhyaya (1994) reports that it is easier for a firm to reorganize if it is in a high-capacity utilization industry. The finding in our paper suggests that the firms that took advantage of the favorable industry conditions at the time of their emergence, without necessarily being healthy enterprises in themselves, are more likely to encounter financial difficulties in the future. Firms that emerge from Chapter 11 protection in spite of hostile industry conditions are more likely to succeed in the future.

Interestingly, the change in the CEO of a firm has an insignificant impact on the hazard. Arguments in the literature suggest that incumbent managers inefficiently continue a losing enterprise when it should have been liquidated (Jensen, 1993; Hotchkiss, 1995). This tendency of managers gives rise to the possibility that firms that undergo reorganization with their original managers are more likely to encounter further financial difficulties. The evidence in this paper suggests that a management change or a lack thereof, does not influence the probability of the firm re-entering bankruptcy. This result is consistent with findings in Hotchkiss and Mooradian (1997), who argue that the dynamics of the bankruptcy process have changed with the rise of "vulture" investors, who frequently take over the management of the firms in which they have invested. Thus, for samples including bankruptcies in the late 1980s and early 1990s management may not be insulated from external discipline.

The demand growth variable has a positive effect on the hazard. This is consistent with Maksimovic and Phillips's (1998) finding that productivity of bankrupt firms in relatively high demand growth industries is lower than their industry counterparts. Thus, reorganized firms from high growth industries are at a greater risk of a second bankruptcy filing since they are more likely to be industry under-performers.

Finally, the total assets, and the GDP growth variables have an insignificant effect on the hazard suggesting that firm size and the general economy wide conditions do not play a significant role in determining the probability of future financial difficulties. Although the literature suggests that larger firms have easier access to financial markets, apparently that alone does not have a significant influence on the firm's ability to ward off future bankruptcy. Similarly, after 
controlling for firms specific and industry characteristics, purely economy wide conditions do not play a major role in determining if the firm will re-file for bankruptcy. ${ }^{12}$

As mentioned in the methodology section, a log-logistic function implies a hazard that declines for sufficiently long durations. The value of $\alpha$ determines the location of the point after which the hazard function declines. In particular, if $\alpha \leq 1$, the hazard declines monotonically; and if $\alpha>1$, the hazard attains a maximum before it begins to decline. The estimated value of $\alpha$ is 1.734 for the standard and 2.210 for the split model, which are both statistically greater than 1 . The plots of the estimated hazard, evaluated at the mean values of the variables, for both models are presented in Fig. 3. Notice that the hazard of the split model increases initially, reaching a peak at about 4 years, and declines sharply thereafter. In comparison, the decline of the hazard of the standard model is very gentle. This result is not surprising since the standard model expects all firms to re-enter bankruptcy and consequently predicts a high hazard even beyond 6 years. The split model suggests a significant decline in the hazard after 4 years since it appropriately takes into account that not all firms will eventually fail. This shape of the estimated hazard for the split model is intuitively appealing. A firm that reorganizes under Chapter 11 has a low instantaneous probability of failure shortly after emergence. However, the firm remains vulnerable to another bankruptcy and this vulnerability increases over time. If the firm is able to endure this increased vulnerability up to a critical time period the probability of re-entering bankruptcy sharply declines.

It should be noted that the hazard stays quite high (about $10 \%$ or more) even up to 6 years after emergence, a finding that is consistent with the histogram in Fig. 2. In fact, the specification of the split model is justified since the estimated hazard (Fig. 3) emulates the actual frequency of bankruptcies (Fig. 2) extremely well. It seems that firms that are reorganized under Chapter 11 stay vulnerable for a relatively long period of time. It can be argued that all firms, including the ones that have never been reorganized, are at some risk of bankruptcy. In fact, after a sufficiently long period of time, some of the effects of the first reorganization wears off and the hazard of the reorganized firm converges to that of any firm. However, the obvious time dependence shown in the early years after reorganization in the plotted hazard indicates that this hazard is associated only with firms that have been reorganized.

In order to examine the influence of various explanatory variables on the hazard more closely, we estimate the average hazard for firms with different values of the variables. For each variable, we divide our sample into quartiles and compute the average quartile value. In Table 3 we present the estimated hazard at year 4 at the average quartiles with the remaining variables at their overall averages. This

\footnotetext{
${ }^{12}$ Results are robust to alternative measures of economic conditions, such as interest rates.
} 


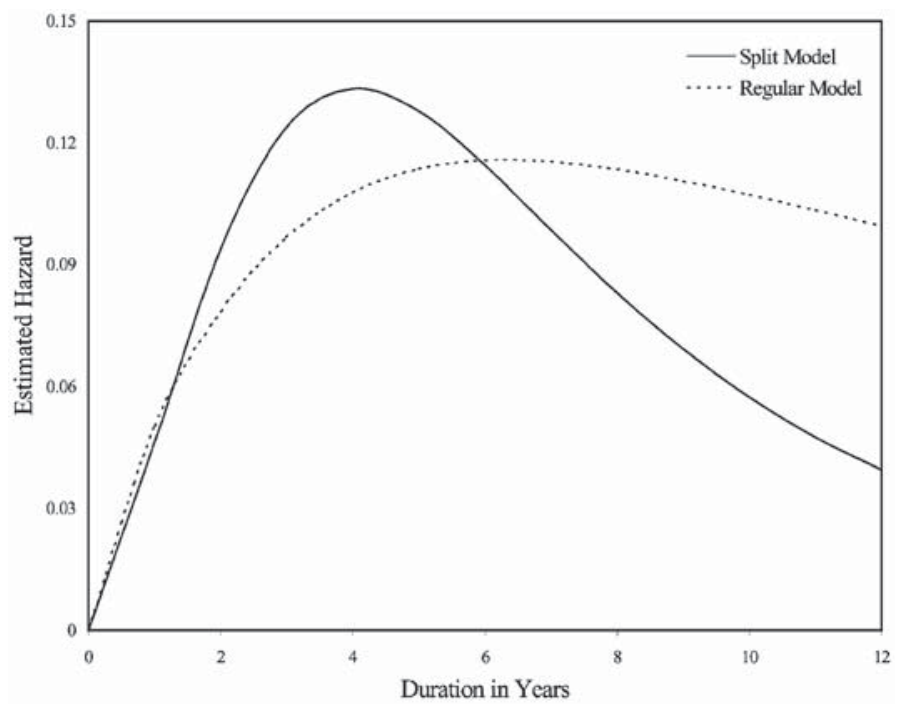

Fig. 3. The estimated hazard of the log-logistic and split-population log-logistic models.

enables us to highlight the magnitude of the influence of each variable on the hazard. For instance, the hazard of an average firm in the first quartile of Change in Debt/Assets is 0.095; this hazard is significantly higher (0.166) for firms that are in the fourth quartile. The hazards of a firm in the first and fourth quartiles of Duration 1 are 0.170 and 0.069 , respectively. Similarly, the average hazard for firms in the fourth quartile of the capacity utilization variable is more than two times than that of firms in the first quartile.

Table 3

Average hazard at year 4 for different quartiles of the explanatory variables

\begin{tabular}{lllll}
\hline Variables & Quartile 1 & Quartile 2 & Quartile 3 & Quartile 4 \\
\hline Duration 1 & 0.170 & 0.157 & 0.123 & 0.069 \\
Log Assets & 0.160 & 0.142 & 0.125 & 0.102 \\
Change in Debt / Assets & 0.095 & 0.123 & 0.138 & 0.166 \\
Change in CEO & 0.121 & 0.121 & 0.144 & 0.144 \\
Change in \#SIC & 0.170 & 0.114 & 0.114 & 0.087 \\
Capacity Utilization & 0.070 & 0.127 & 0.154 & 0.168 \\
Demand Growth & 0.110 & 0.123 & 0.137 & 0.158 \\
GDP Growth & 0.116 & 0.129 & 0.140 & 0.146 \\
\hline
\end{tabular}

- The hazard is computed from the estimated split-population log-logistic duration model.

- The hazard is estimated for different quartiles of a given variable with the remaining variables evaluated at their means. 


\section{Conclusion}

For the stakeholders of a firm it is important to know what the future prospects of the firm are after a reorganization under Chapter 11. Would the firm re-file for Chapter 11 or liquidate, and if so when, or would it continue to operate successfully? In this paper we examine if a reorganized firm will eventually go bankrupt and when for a vulnerable firm this will happen. Firms that emerge from Chapter 11 protection are observed over time and their performance after emergence is recorded. We use a split-population duration model that controls for the fact that some firms may never go bankrupt once they have emerged from Chapter 11. We find that the probability of an average firm eventually re-entering bankruptcy is $73 \%$.

It has been documented that the financial woes of a firm are not only due to factors that are firm specific but also are linked to industry conditions. In a similar vein, one could argue that a re-occurrence of bankruptcy could be due to actions taken by the firm during re- organization or industry and economy-wide factors could dictate it. We use both sets of factors to estimate the vulnerability of a firm to another bankruptcy after it has been re- organized under Chapter 11. Of the firm specific variables, we find that this vulnerability is lower for firms that have spent a longer period of time under Chapter 11 protection, have lowered their leverage, and have retained a larger number of lines of businesses. The industry conditions also play a critical role in the re-occurrence of bankruptcy. We find that firms in the highest quartile of industry capacity utilization are more than two times more vulnerable than firms in the lowest quartile. Firms from high demand growth industries are more likely to file for another bankruptcy.

The estimated hazard increases initially and then begins to decline after approximately 4 years, implying that the instantaneous probability of a firm re-entering bankruptcy continues to increase up to 4 years. Furthermore, we find that this probability, although on the decline, remains high for almost 6 years after emergence. This suggests that the financial woes of a reorganized firm persist for a significant length of time. The vulnerability of a reorganized firm over a relatively long period of time, and the influence of various aspects of reorganization and industry conditions on this vulnerability has important implications for the creditors and the stockholders of the firm and also for policy makers who monitor the bankruptcy process.

\section{References}

Alderson, M., Betker, B., 1995. Liquidation Versus Continuation: Did Reorganized Firms Do the Right Thing? Working Paper, Ohio State University.

Baek, I., Bandopadhyaya, A., 1996. The determinants of the duration of commercial bank debt rescheduling for sovereigns. Journal of Banking and Finance 20 (4), 673-686. 
Bandopadhyaya, A., 1994. An estimation of the hazard rate of firms under Chapter 11 protection. The Review of Economics and Statistics, 346-350.

Bebchuk, L., Chang, H.F., 1992. Bargaining and the division of value in corporate reorganizations. Journal of Law, Economics and Organization 8, 253-279.

Boot, A.W.A., 1992. Why hang on to losers? Divestitures and takeovers. Journal of Finance XVII (4), 1401-1423, September.

Casey, J.C., McGee, V.E., Stickney, C.P., 1986. Discriminating between reorganized and liquidated firms in bankruptcy. The Accounting Review LXI (2), 249-262, April.

Gilson, S., 1996. Transactions costs and capital structure choice: evidence from financially distressed firms. The Journal of Finance 52 (1), 161-196, March.

Gilson, S., John, K., Lang, L.H.P., 1990. Troubled debt restructuring: an empirical study of private reorganization of firms in default. Journal of Financial Economics, 315-353, October.

Gucht, L.M., Moore, W.T., 1998. Predicting the duration and reversal probability of leveraged buyouts. Journal of Empirical Finance 5, 299-315.

Harris, M., Raviv, A., 1990. Capital structure and the informational role of debt. Journal of Finance 45, 321-349.

Hart, O., Moore, J., 1995. Debt and seniority: an analysis of hard claims in constraining management. American Economic Review 85, 567-587.

Hotchkiss, E.S., 1995. The post-bankruptcy performance of firms emerging from Chapter 11. The Journal of Finance 50 (1), 3-21, March.

Hotchkiss, E.S., Mooradian, R.M., 1997. Vulture investors and the market for control of distressed firms. Journal of Financial Economics 43 (3), 401-432.

Jaggia, S., Thosar, S., 1995. Contested tender offers: an estimate of the hazard function. Journal of Business and Economic Statistics 13, 113-119.

Jensen, M.C., 1989. Active investors, LBOs, and the privatization of bankruptcy. Journal of Applied Corporate Finance, 35-44, Spring.

Jensen, M.C., 1993. The modern industrial revolution, exit, and the failure of internal control systems. The Journal of Finance XLVIII (3), 831-880, July.

John, K., Lang, L.H.P., Netter, J., 1992. The voluntary restructuring of large firms in response to performance decline. The Journal of Finance 47, 891-918.

Kiefer, N.M., 1988. Econometric duration data and hazard functions. Journal of Economic Literature 25, 646-679.

Lang, L.H.P., Stulz, R., 1992. Contagion and competitive intra-industry effects of bankruptcy announcements. Journal of Financial Economics 32, 45-60.

LoPucki, L.M., Whitford, W.C., 1993. Patterns in the reorganization of large, publicly held companies. Cornell Law Review 78, 597-618.

Maksimovic, V., Phillips, G., 1998. Asset efficiency and reallocation decisions of bankrupt firms. The Journal of Finance 53 (1495), 38.

Mooradian, R.M., 1994. The effect of bankruptcy protection on investment: Chapter 11 as a screening device. Journal of Finance 49, 1403-1430.

Opler, T.C., Titman, S., 1994. Financial distress and corporate performance. Journal of Finance 49, 1015-1040.

Schmidt, P., Witte, A.D., 1989. Predicting criminal recidivism using split population survival time model. Journal of Econometrics 40, 141-159.

Shleifer, A., Vishny, R., 1992. Liquidation values and debt capacity: a market equilibrium approach. The Journal of Finance 47, 1343-1367.

White, M.J., 1984. Bankruptcy liquidation and reorganization. In: Logue, D. (Ed.), Handbook of Modern Finance. Warren, Gorham and Lamont. 